\title{
Diode laser treatment for retinopathy of prematurity: structural and functional outcome
}

\author{
C S Ling, B W Fleck, E Wright, C Anderson, I Laing
}

\begin{abstract}
Aims-The anatomical and functional outcome of 13 babies with retinopathy of prematurity (ROP) treated with binocular indirect ophthalmoscope diode laser photocoagulation was assessed.

Methods-Thirteen babies ( 25 eyes) at median postmenstrual age (PMA) 25.5 weeks and median birth weight $725 \mathrm{~g}$ were treated with binocular indirect ophthalmoscope (BIO) diode laser photocoagulation when threshold retinopathy of prematurity (ROP) was detected at median PMA 35 weeks. Retinopathy was more severe in the nasal retina in 15 eyes. The median severity of retinopathy was 6 clock hours grade 3 disease. All babies were treated under general anaesthetic with no significant ocular or systemic complications during treatment. The median number of burns was 1200 .

Results-Resolution of active retinopathy occurred 1-2 weeks following treatment in all but one baby. All eyes had favourable anatomical and functional outcome as defined by the Cryo-ROP study group at a median age of 19.5 months of follow up.

Conclusion-BIO diode laser treatment is as effective as cryotherapy with less morbidity.

(Br f Ophthalmol 1995; 79: 637-641)
\end{abstract}

While recent comprehensive UK figures are not available, studies in Ireland ${ }^{1}$ and Scotland ${ }^{2}$ suggest that retinopathy of prematurity (ROP) currently accounts for approximately $10 \%$ of childhood blindness. Retinal cryotherapy has been demonstrated to reduce the incidence of blindness following the onset of 'threshold' disease. ${ }^{3}$ However, retinal cryotherapy in premature neonates can result in ocular 45 and systemic ${ }^{5} 6$ morbidity.

Early Japanese experience with xenon photocoagulation treatment of ROP, ${ }^{7}$ and extensive experience with the use of argon and diode laser photocoagulation for retinal neovascular conditions in adults lead us to consider binocular indirect ophthalmoscope (BIO) laser photocoagulation as an alternative treatment. We began to use BIO diode laser photocoagulation in 1991, initially as a supplement to cryotherapy. From mid 1992 onwards BIO diode laser photocoagulation was used as the primary treatment of all cases of threshold ROP and we report the anatomical and functional outcome of the 13 babies treated during the period November 1992-November 1993.
Materials and methods

All infants in one regional neonatal intensive care unit who developed threshold ROP during the period November 1992-3 were studied. Screening examinations were performed from 31 weeks postmenstrual age at 2 weekly intervals, increasing to weekly intervals when any grade of retinopathy was detected. The international classification of ROP was used. ${ }^{8}$ Zone 2 was further subdivided into anterior, mid and posterior zone 2 for descriptive purposes. Posterior vessel dilatation and tortuosity were subdivided into mild, moderate, or severe 'plus' disease.

The treatment criteria were those used in the Cryo-ROP study. ${ }^{4}$ The 'threshold' for treatment was defined as grade 3 ROP in zone 1 or 2 of at least 5 contiguous or 8 cumulative clock hours in extent, associated with 'plus' disease. ${ }^{3}$ Treatment was performed within 72 hours of the diagnosis of 'threshold' disease.

Informed consent was obtained in each case (Appendix). The treatment was performed in the neonatal intensive care unit, within a room screened for laser use. The pupils were dilated using drops of tropicamide $0.5 \%$ and phenylephrine $2.5 \%$ instilled 30 and 15 minutes before treatment. ${ }^{9}$ All infants were paralysed and ventilated using intravenous morphine and pancuronium, administered by a neonatologist. A Nidek 1200 BIO diode laser was used for all treatments. Treatment was directed to all avascular retina anterior to the ROP ridge. Burns were spaced with a gap of approximately half a burn width between each burn, using enough energy to produce light grey/cream burns, avoiding intense white, full thickness burns. Posterior areas were treated without scleral indentation, and higher energy was needed to treat these areas. More anterior areas were treated using scleral indentation. An irrigating vectis connected to a $2 \mathrm{ml}$ syringe containing saline was found to be convenient for this purpose, allowing frequent irrigation of the cornea during treatment. All treatments were performed by one ophthalmologist (BWF).

Extubation was performed within 24 hours of treatment. Post-treatment eyedrops were not used. Babies were reviewed weekly until all ROP has resolved. Retreatment was performed if areas of grade 3 retinopathy persisted in association with areas of untreated retina.

Follow up examinations were performed at 6,12 , and 18 months corrected postnatal age. A favourable anatomical outcome was defined as a normal posterior fundus on BIO examination, carried out by one observer who had not performed the treatments (EW). Refraction was measured using retinoscopy by one 
Table 1 Clinical data of infants

\begin{tabular}{|c|c|c|c|c|c|c|c|c|}
\hline $\begin{array}{l}\text { Baby } \\
\text { No }\end{array}$ & $\begin{array}{l}\text { Birth } \\
\text { weight } \\
\text { (g) }\end{array}$ & $\begin{array}{l}\text { Post } \\
\text { menstrual } \\
\text { age (weeks) } \\
\text { at birth }\end{array}$ & Sex & Twin & $\begin{array}{l}\text { Intraventricular } \\
\text { haemorrhage }\end{array}$ & $\begin{array}{l}\text { First } \\
\text { examined } \\
P M A \\
\text { (weeks) }\end{array}$ & $\begin{array}{l}\text { Threshold } \\
\text { disease } \\
\text { PMA } \\
\text { (weeks) }\end{array}$ & $\begin{array}{l}\text { Treatment } \\
\text { PMA } \\
\text { (weeks) }\end{array}$ \\
\hline $\begin{array}{r}1 \\
2 \\
3 \\
4 \\
5 \\
6 \\
7 \\
8 \\
9 \\
10 \\
11 \\
12 \\
13\end{array}$ & $\begin{array}{l}692 \\
739 \\
710 \\
724 \\
589 \\
727 \\
887 \\
788 \\
840 \\
725 \\
710 \\
784 \\
665\end{array}$ & $\begin{array}{l}24 \\
24 \\
25 \\
25 \\
25 \\
27 \\
27 \\
25 \\
25 \\
26 \\
25 \\
25 \\
24\end{array}$ & $\begin{array}{l}F \\
M \\
M \\
F \\
F \\
F \\
F \\
M \\
M \\
M \\
F \\
F \\
F\end{array}$ & $\begin{array}{l}\mathbf{Y} \\
\mathbf{Y} \\
\mathbf{Y} \\
\mathbf{Y} \\
\mathbf{N} \\
\mathbf{N} \\
\mathbf{Y} \\
\mathbf{N} \\
\mathbf{N} \\
\mathbf{N} \\
\mathbf{N} \\
\mathbf{Y} \\
\mathbf{N}\end{array}$ & $\begin{array}{l}\mathbf{N} \\
\mathbf{N} \\
\mathbf{N} \\
\mathbf{N} \\
\mathbf{N} \\
\mathbf{N} \\
\mathbf{N} \\
\mathbf{N} \\
\mathbf{N} \\
\mathbf{Y} \\
\mathbf{N} \\
\mathbf{N} \\
\mathbf{Y}\end{array}$ & $\begin{array}{l}31 \\
31 \\
30 \\
30 \\
31 \\
32 \\
31 \\
31 \\
30 \\
32 \\
32 \\
32 \\
31\end{array}$ & $\begin{array}{l}33 \\
33 \\
37 \\
35 \\
36 \\
41 \\
36 \\
35 \\
35 \\
36 \\
32 \\
35 \\
32\end{array}$ & $\begin{array}{l}33 \\
33 \\
38 \\
35(38) \\
36 \\
41 \\
36 \\
35 \\
35 \\
36 \\
32 \\
35 \\
32\end{array}$ \\
\hline \multicolumn{6}{|c|}{$\begin{array}{ll}\text { Median } 725 & 25 \cdot 5 \\
\text { Range } 589-887 & 24-27\end{array}$} & $\begin{array}{l}31 \\
30-32\end{array}$ & $\begin{array}{l}35 \\
32-41\end{array}$ & $\begin{array}{l}35 \\
32-41\end{array}$ \\
\hline
\end{tabular}

Baby 4 was treated at 35 weeks PMA and retreated at 38 weeks PMA.

observer (EW) at least 30 minutes after the instillation of one drop of cyclopentolate $1 \%$. Functional outcomes were assessed using Keeler preferential looking cards by one observer (CA). A favourable functional outcome was grating acuity greater than or equal to 0.8 cycles per degree as defined by the CryoROP study at 1 year follow up. ${ }^{10}$

\section{Results}

Thirteen infants (25 eyes) were treated during the study period. Table 1 summarises the neonatal data of the infants. All infants were white. Postmenstrual age at birth ranged from 24-27 weeks, with a median of $25 \cdot 5$ weeks. Birth weights were $589-887 \mathrm{~g}$ with a median of $725 \mathrm{~g}$. There were eight females and five males. Six of the infants were twins. Two had intraventricular brain haemorrhages, one bilateral and one right sided.

The infants were first examined at 30-32 weeks, median 31 weeks. Threshold disease was detected at 32-41 weeks, median 35 weeks.

Table 2 gives the retinopathy findings. Twenty eyes had mid zone 2 disease and four had posterior zone 2 disease. Plus disease consisted of mild or moderately severe posterior vessel dilatation and tortuosity in all cases. Grade 3 ROP first appeared in the nasal retina of 15 eyes, the temporal retina of four eyes, and the nasal and temporal retina equally in six eyes. In baby 4 retinopathy was confined to the nasal retina initially, and only the nasal

Table 2 Retinopathy data

\begin{tabular}{|c|c|c|c|c|c|c|c|c|}
\hline \multirow{2}{*}{$\begin{array}{l}\text { Baby } \\
\text { No }\end{array}$} & \multicolumn{2}{|l|}{$\begin{array}{l}\text { Clock } \\
\text { hours }\end{array}$} & \multicolumn{2}{|l|}{ Zones } & \multicolumn{2}{|c|}{$\begin{array}{l}\text { Posterior } \\
\text { plus disease }\end{array}$} & \multicolumn{2}{|c|}{$\begin{array}{l}\text { Area in which grade } 3 \\
\text { ROP first evident }\end{array}$} \\
\hline & $R$ & $L$ & $R$ & $L$ & $R$ & $L$ & $R$ & $L$ \\
\hline $\begin{array}{r}1 \\
2 \\
3 \\
4 \\
5 \\
6 \\
7 \\
8 \\
9 \\
10 \\
11 \\
12 \\
13\end{array}$ & $\begin{array}{l}8 \\
8 \\
5 \\
5(4) \\
8 \\
3 \\
5 \\
5 \\
6 \\
8 \\
12 \\
6 \\
6\end{array}$ & $\begin{array}{l}8 \\
8 \\
5 \\
6(4) \\
1 \\
5 \\
2 \\
5 \\
6 \\
8 \\
8 \\
6 \\
5\end{array}$ & $\begin{array}{l}\text { Mid2 } \\
\text { Mid2 } \\
\text { Mid2 } \\
\text { Mid2 } \\
\text { Mid2 } \\
3 \\
\text { Mid2 } \\
\text { Mid2 } \\
\text { Mid2 } \\
\text { Mid2 } \\
\text { Post2 } \\
\text { Mid2 } \\
\text { Post2 }\end{array}$ & $\begin{array}{l}\text { Mid2 } \\
\text { Mid2 } \\
\text { Mid2 } \\
\text { Mid2 } \\
\text { Mid2 } \\
\text { Ant2 } \\
\text { Mid2 } \\
\text { Mid2 } \\
\text { Mid2 } \\
\text { Mid2 } \\
\text { Post2 } \\
\text { Mid2 } \\
\text { Post2 }\end{array}$ & $\begin{array}{l}\text { Mild } \\
\text { Mild } \\
\text { Mild } \\
\text { Mod } \\
\text { Mild } \\
\text { Mild } \\
\text { Mild } \\
\text { Mild } \\
\text { Mod } \\
\text { Mod } \\
\text { Mild } \\
\text { Mild } \\
\text { Mild }\end{array}$ & $\begin{array}{l}\text { Mild } \\
\text { Mild } \\
\text { Mild } \\
\text { Mod } \\
\text { Mild } \\
\text { Mild } \\
\text { Mild } \\
\text { Mild } \\
\text { Mod } \\
\text { Mod } \\
\text { Mod } \\
\text { Mild } \\
\text { Nil }\end{array}$ & $\begin{array}{l}\text { Nasal } \\
\text { Nasal } \\
\text { Nasal } \\
\text { Nasal (temp) } \\
\text { Nasal/temp } \\
\text { Temp } \\
\text { Temp } \\
\text { Nasal } \\
\text { Nasal } \\
\text { Nasal/temp } \\
\text { Nasal/temp } \\
\text { Nasal } \\
\text { Nasal/temp }\end{array}$ & $\begin{array}{l}\text { Nasal } \\
\text { Nasal } \\
\text { Nasal } \\
\text { Nasal (temp) } \\
\text { Temp } \\
\text { Temp } \\
\text { Temp } \\
\text { Nasal } \\
\text { Nasal } \\
\text { Nasal/temp } \\
\text { Nasal/temp } \\
\text { Nasal } \\
\text { Nasal }\end{array}$ \\
\hline
\end{tabular}

Temp $=$ temporal, $\bmod =$ moderate. avascular retina was treated. However, 3 weeks later the temporal retina developed grade 3 retinopathy and required treatment. In the remaining 12 infants all avascular retina was treated at the first treatment session. In baby 6 , the right eye did not reach threshold disease.

Table 3 summarises the treatments. The median number of burns applied to each eye was 1200 , with a range of 350-2500. The power used was $0.3-0.6 \mathrm{~W}$. All burns were of $0 \cdot 2$ second duration. The times to resolution of retinopathy and resolution of plus disease were similar. Plus disease resolved within 1 week in eight infants, 1-2 weeks in three infants, and 2-3 weeks in one infant. Baby 4 was retreated at 3 weeks, and retinopathy and plus disease then resolved within 1 week.

No operative or postoperative laser complications were noted. There were no systemic complications during treatment. Ten infants were extubated within 24 hours of treatment, one 36 hours, and one 48 hours after treatment. One baby developed Escherischia coli pneumonia and was ventilated for 1 week. No other systemic complications were noted. All eyes had favourable anatomical outcomes as defined in the Cryo-ROP study. ${ }^{10}$ Table 4 summarises the functional outcomes. The median age at follow up was 19.5 (range 9.7-25.5) months. Three children had strabismus, two infantile esotropia (babies 8 and 10), and one exotropia (baby 9). In all babies grating visual acuity using Keeler preferential looking cards was obtained. Visual acuity ranged from 2.9 to 14.5 cycles per degree. In six babies uniocular acuity in each eye was obtained and in seven babies only binocular acuity could be obtained. All babies fell within the Cryo-ROP definition of favourable acuity for 1 year of age $(0.8$ cycles per degree uniocular). Only one baby (baby 4) was myopic, with a refraction of -1.50 dioptres in each eye. All other babies had low degrees of hypermetropia.

\section{Discussion}

Several reports of BIO diode laser photocoagulation treatment of ROP have now been published. ${ }^{1-16} \mathrm{BIO}$ argon laser photocoagulation has also been reported. ${ }^{1417}$ A large scale multicentre comparison of cryotherapy and BIO diode laser photocoagulation treatment of ROP is unlikely to be feasible, ${ }^{18}$ and metaanalysis of existing single centre comparisons of these treatments is of limited value. ${ }^{18}$

There have been two studies in which one eye was treated with cryotherapy and one with BIO diode laser photocoagulation. ${ }^{12} 15$ The treatments appeared to produce similar anatomical outcome. Very little information is available on the functional outcome of BIO diode laser photocoagulation treatment of ROP.

We have previously published our results of cryotherapy of threshold ROP, 5 but historical comparison with $\mathrm{BIO}$ diode laser photocoagulation is of limited value as neonatal intensive care medicine is a rapidly changing discipline. ${ }^{4}$

The median PMA at birth of 25.5 weeks, 
Table 3 Treatment data

\begin{tabular}{|c|c|c|c|c|c|c|c|c|}
\hline \multirow{2}{*}{$\begin{array}{l}\text { Baby } \\
\text { No }\end{array}$} & \multicolumn{2}{|c|}{ No of burns } & \multicolumn{2}{|c|}{ Power (W) } & \multicolumn{2}{|c|}{$\begin{array}{l}\text { Time to resolution } \\
\text { of plus (days) }\end{array}$} & \multicolumn{2}{|c|}{$\begin{array}{l}\text { Time to resolution of } \\
\text { retinopathy (days) }\end{array}$} \\
\hline & $R$ & $L$ & $R$ & $L$ & $R$ & $L$ & $R$ & $L$ \\
\hline $\begin{array}{l}1 \\
2 \\
3 \\
4 \\
\star\end{array}$ & $\begin{array}{r}2000 \\
2000 \\
2500 \\
650 \\
1050\end{array}$ & $\begin{array}{r}2000 \\
2000 \\
2500 \\
650 \\
1000\end{array}$ & $\begin{array}{l}0.35 \\
0.37 \\
0.37 \\
0.55\end{array}$ & $\begin{array}{l}0.35 \\
0.37 \\
0.37 \\
0.60\end{array}$ & $\begin{array}{l}7 \\
7 \\
7 \\
\star\end{array}$ & $\begin{array}{l}7 \\
7 \\
7 \\
\star\end{array}$ & $\begin{array}{l}7 \\
7 \\
7 \\
\star\end{array}$ & $\begin{array}{l}7 \\
7 \\
7 \\
\star\end{array}$ \\
\hline $\begin{array}{r}5 \\
6 \\
7 \\
8 \\
9 \\
10 \\
11 \\
12 \\
13\end{array}$ & $\begin{array}{r}800 \\
- \\
700 \\
1350 \\
1200 \\
520 \\
1000 \\
1200 \\
1400\end{array}$ & $\begin{array}{r}800 \\
350 \\
700 \\
1350 \\
1200 \\
520 \\
1000 \\
1200 \\
1400\end{array}$ & $\begin{array}{l}0.37 \\
- \\
0.35 \\
0.35 \\
0.35 \\
0.55 \\
0.31 \\
0.37 \\
0.35\end{array}$ & $\begin{array}{l}0.37 \\
0.35 \\
0.35 \\
0.35 \\
0.35 \\
0.57 \\
0.31 \\
0.37 \\
0.40\end{array}$ & $\begin{array}{r}14 \\
- \\
21 \\
14 \\
14 \\
7 \\
5 \\
6 \\
5\end{array}$ & $\begin{array}{r}14 \\
7 \\
21 \\
14 \\
14 \\
7 \\
5 \\
6 \\
5\end{array}$ & $\begin{array}{r}14 \\
\overline{7} \\
14 \\
14 \\
7 \\
5 \\
6 \\
5\end{array}$ & $\begin{array}{r}14 \\
7 \\
7 \\
14 \\
14 \\
7 \\
5 \\
6 \\
5\end{array}$ \\
\hline $\begin{array}{l}\text { Median } \\
\text { Range }\end{array}$ & \multicolumn{2}{|c|}{$\begin{array}{l}1200 \\
350-2500\end{array}$} & \multicolumn{2}{|c|}{$0.30-0.60$} & $5-21$ & $5-21$ & $5-14$ & $5-14$ \\
\hline
\end{tabular}

${ }^{\star}$ Retreated at 3 weeks. Treatments of babies 4 and 10 were supplemented with a small number (8-12) of anteriorly placed cryotherapy applications in each eye.

and birth weight of $725 \mathrm{~g}$ in our current study are similar to those reported in previous studies of BIO diode laser photocoagulation. ${ }^{12-16}$ Infants reported in our cryotherapy study had a mean PMA at birth of $25 \cdot 1$ weeks, and birth weight of $765 \mathrm{~g}^{5}$ while infants in the CryoROP study had a PMA at birth of 26.3 weeks, and birth weight of $800 \mathrm{~g}^{3}$

The median PMA at which threshold disease was detected, 35 weeks, was also similar to several previous reports of BIO diode laser photocoagulation, ${ }^{11} 131416$ but slightly earlier than the two randomised comparisons of cryotherapy and BIO laser photocoagulation treatment, $^{1215}$ in which the mean PMA at treatment was approximately 37 weeks. The Cryo-ROP study ${ }^{3}$ reported a slightly later PMA at treatment - 37.7 weeks. In our cryotherapy study, ${ }^{5}$ the PMA was similar at $35 \cdot 1$ weeks.

The severity of retinopathy at the time of treatment (a median of 6 clock hours of grade 3 disease) was similar to previous studies of BIO diode laser photocoagulation, ${ }^{11}{ }^{13-15}$ but was less severe than our cryotherapy study (a mean of 8.5 clock hours of grade 3 disease), ${ }^{5}$ or the Cryo-ROP study (a mean of 9.7 clock hours of grade 3 disease). ${ }^{3}$

For all of the above reasons historical comparison of cryotherapy with BIO diode laser photocoagulation is not valid.

Table 4 Functional outcome

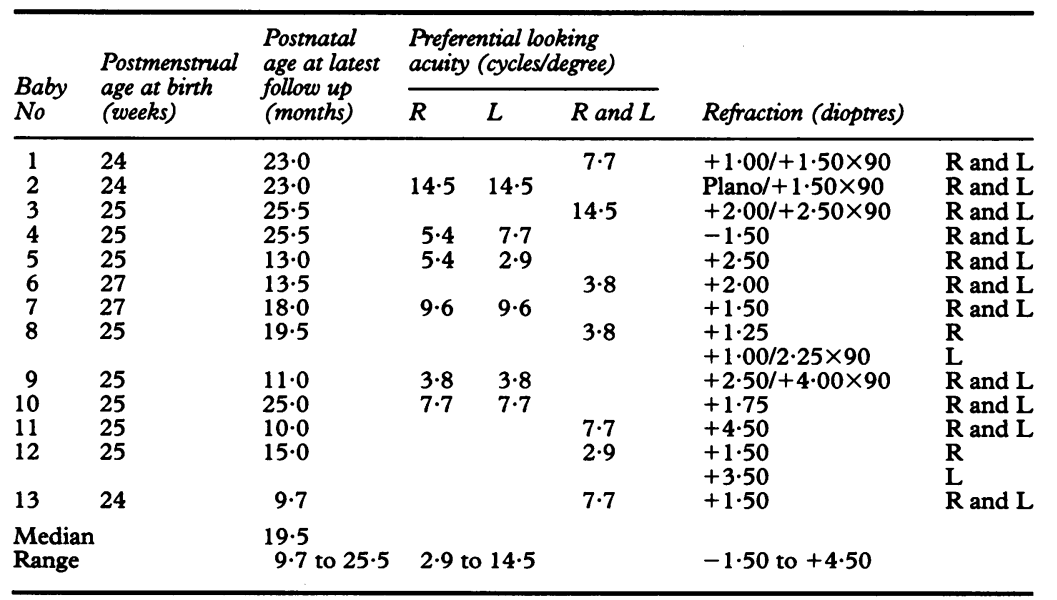

Preferential looking acuities for babies $1,3,6,8,11,12$, and 13 were binocular.
Our findings of early nasal quadrant retinopathy in the majority of infants confirms natural history data reported by Fielder. ${ }^{19}$

We opted to perform all treatments in the neonatal intensive care unit using a 'general anaesthetic', following our experience with cryotherapy. ${ }^{5}$ Several centres have reported the use of sedation and topical anaesthetic for BIO diode laser photocoagulation. ${ }^{11-16}$ However, we have found the routine use of intravenous pancuronium and morphine with endotracheal intubation and ventilation allows optimal treatment conditions. Complete laser treatment cover of avascular retina can be consistently achieved in these conditions and our one retreatment was precipitated by development of new areas of retinopathy rather than by areas 'missed' on primary treatment. The infants remained very stable during treatment and early extubation following treatment was normally possible. One infant developed pneumonia following treatment, but had had copious respiratory secretions for several days before treatment.

We used a median number of 1200 burns per eye to cover completely all avascular retina from the ROP ridge to the ora serrata. This is more treatment than that reported from some other centres, ${ }^{11} 151618$ but we were aiming to treat all avascular retina at one session. In one baby retinopathy was confined to the nasal retina at the time of primary treatment and the temporal avascular retina was not treated (baby 4). However, grade 3 retinopathy subsequently developed in the temporal quadrants necessitating a second treatment session. We prefer to treat anteriorly up to the ora serrata in order to minimise the risk of iris neovascularisation and rubeotic glaucoma. ${ }^{20}$

There were no instances of significant ocular or systemic complications during treatment. Vitreous haemorrhage has been reported following BIO diode laser photocoagulation, 1214 as has choroidal haemorrhage ${ }^{1215}$ and hyphaema. ${ }^{13}$ BIO argon laser treatment has been reported to cause tunica vasculosa lentis and anterior capsule burns. ${ }^{1421}$ Apart from minimal hyperaemia there were no ocular complications in the post-treatment period. In contrast we have found that cryotherapy produces significant ocular morbidity at the time of treatment. ${ }^{5}$ We have previously reported vitreous haemorrhage and eyelid burns ${ }^{5}$ in addition to the universal presence of conjunctival and eyelid oedema after cryotherapy. These complications were also reported in the CryoROP study. ${ }^{3}$ There were no significant systemic complications during any of our treatments. BIO diode laser photocoagulation is probably less stressful but this has not been formally measured and a prospective trial to do so probably would not be feasible. Respiratory and cardiovascular complications have been reported following both BIO laser photocoagulation ${ }^{11-16}$ and cryotherapy ${ }^{35}$ when these were performed using sedation and local anaesthetic. Our preference therefore remains the use of a 'general anaesthetic'.

'Plus' disease and active retinopathy resolved 1-2 weeks after treatment in all but 
one baby. The timescale of resolution of plus disease following treatment has not been widely reported but our findings are similar to those of one previous report. ${ }^{11}$ The timescale of resolution of retinopathy following cryotherapy has not been formally reported but it is our impression that BIO diode laser photocoagulation and cryotherapy produce a similar rate of resolution of retinopathy.

The anatomical outcome of the small number of babies reported in this paper has been good. Other reports of BIO laser photocoagulation also appear to show a relatively low rate of anatomical failure. ${ }^{11-16}$

The Cryo-ROP study at 1 year follow up reported anatomical failure in $25.7 \%$ of eyes treated by cryotherapy, ${ }^{10}$ and we have reported anatomical failure in $20 \%$ of eyes treated by cryotherapy. ${ }^{5}$ However, historical comparisons with cryotherapy are not valid as outlined above, and the two comparisons of cryotherapy and BIO diode laser photocoagulation that have been made showed no difference in anatomical outcome. ${ }^{1215}$

The Cryo-ROP study defined favourable functional outcome at 1 year follow up as grating acuity greater than or equal to 0.8 cycles per degree, and a $65 \%$ favourable outcome was reported. ${ }^{10}$ In our series, all eyes had favourable functional outcome as defined by the Cryo-ROP study at a median age of 19.7 months. This result may represent an overestimate of visual acuity as in seven babies only binocular visual acuity could be obtained. The favourable functional outcome of the CryoROP study was better at 1 year than at $3 \frac{1}{2}$ years of follow up. This may have been due to the lower favourable acuity values defined by the Cryo-ROP study at 1 year of age. The Cryo-ROP study at $3 \frac{1}{2}$ years of follow up defined favourable functional outcome as grating acuity greater than or equal to 6.4 cycles per degree. ${ }^{22}$ Using this criterion, the favourable functional outcome in our series was $60 \%$. The small numbers involved in our study make functional outcome comparison with the Cryo-ROP study invalid. Further follow up of our patients with optotype visual acuity testing at an older age will give a more complete evaluation of the functional results.

Previous reports have documented the development of myopia in premature, low birthweight infants ${ }^{2324}$ with or without retinopathy of prematurity..$^{25} 26$ There was a trend towards myopia in eyes that received cryotherapy in the Cryo-ROP study but the significance is unclear. ${ }^{1022}$ In contrast, most of our babies $(92 \%)$ had a hypermetropic refraction at a median age of 19.5 months.

In summary, in our experience diode laser treatment appears to be as effective as cryotherapy with less morbidity.

1 Goggin $M$, O'Keefe $M$. Childhood blindness in the Republic of Ireland: a national survey. $\mathrm{Br} \mathcal{F}$ Ophthalmol 1991; 75: 425-9.

2 Fleck BW, Dangata Y. Causes of visual handicap in the Royal Blind School, Edinburgh, 1991-2. Br fOphthalmol Royal Blind Scho

3 Cryotherapy for Retinopathy of Prematurity Cooperative Group. Multicentre trial of cryotherapy for retinopathy of prematurity. Three month outcome. Arch Ophthalmol 1990; 108: 195-204.
4 Cryotherapy for Retinopathy of Prematurity Cooperative Group. Multicentre trial of cryotherapy for retinopathy
prematurity. Preliminary results. Arch Ophthalmol 1988; prematurity

5 Dhillon B, Wright E, Laing I, Fleck BW. Cryotherapy for retinopathy of prematurity in a regional neonatal intensive care unit. $\mathcal{F} R$ Coll Surg Edinb 1992; 37: 83-8.

6 Brown GC, Tasman WD, Naidoff M, Schaffer DB, Quinn G, Bhutani VK. Systemic complications associated with retinal cryoablation for retinopathy of prematurity. Ophthalmology 1990; 97: 855-8.

7 Nagata M, Kobayashi Y, Fukuda H, Suekane K. Photocoagulation for the treatment of retinopathy of prematurity. Fpn ₹ Clin Ophthalmol 1968; 22: 419-27.

8 International Committee. An international classification of retinopathy of prematurity. $\mathrm{Br} \mathcal{f}$ Ophthalmol 1984; 68: 690-7.

9 Fleck BW, Dhillon B, Mitchell A. Additive mydriatic effect of $2.5 \%$ phenylephrine and $0.5 \%$ tropicamide eyedrops in premature babies. $\mathcal{F}$ Pediatr Ophthalmol Strabismus 1994; 31: $130-1$.

10 Cryotherapy for Retinopathy of Prematurity Cooperative Group. Multicentre trial of cryotherapy for retinopathy of prematurity. One year outcome - structure and function. Arch Ophthalmol 1990; 108: 1408-16.

11 Goggin M, O'Keefe M. Diode laser for retinopathy of prematurity - early outcome. Br f Ophthalmol 1993; 77: maturity

12 McNamara JA, Tasman W, Vander JF, Brown GC. Diode laser photocoagulation for retinopathy of prematurity. Preliminary results. Arch Ophthalmol 1992; 110: 1714-6.

13 Capone A, Diaz-Rohena R, Sternberg P, Mandell B, Lambert HM, Lopez PF. Diode laser photocoagulation for zone 1 threshold retinopathy of prematurity. $\mathrm{Am} \mathcal{F}$ Ophthalmol 1993; 116: 444-50.

14 Benner JD, Morse LS, Hay A, Landers III MB. A comparison of argon and diode photocoagulation combined with supplemental oxygen for the treatment of retinopathy of prematurity. Retina 1993; 13: 222-9.

15 Hunter DG, Repka MX. Diode laser photocoagulation for threshold retinopathy of prematurity: a randomised study. threshold retinopathy of prematurity:

16 Fleming TN, Runge PE, Charles ST. Diode laser photocoagulation for prethreshold posterior retinopathy of prematurity. Am f Ophthalmol 1992; 114: 589-92.

17 Landers MB, Toth CA, Semple HC, Morse LS. Treatment of retinopathy of prematurity with argon laser photocoagulation. Arch Ophthalmol 1992; 110: 44-7.

18 The Laser ROP Study Group. Laser therapy for retinopathy of prematurity. Arch Ophthalmol 1994; 112: 154-6.

19 Fielder AR, Shaw DE, Robinson J, Ng YK. Natural history of retinopathy of prematurity: a prospective study. Eye 1992; 6: 233-42.

20 Dhillon B, Butt Z, Fleck B. Rubeotic glaucoma and retinopathy of prematurity: a case report. $f$ Paediatr Ophthalmol Strabismus 1992; 29: 123-5.

21 Pogrebniak AE, Bolling JP, Steward MW. Argon laserinduced cataract in an infant with retinopathy of prematurity. Am $\mathcal{F}$ Ophthalmol 1994; 2: 261-2.

22 Cryotherapy for Retinopathy of Prematurity Cooperative Group. Multicentre trial of cryotherapy for retinopathy of prematurity. Three and half-year outcome - structure and function. Arch Ophthalmol 1993; 111: 339-44.

23 Page JM, Schneeweiss S, Whyte HE, Harvey P. Ocular sequelae in premature infants. Paediatrics 1993; 92: 789-90.

24 Quinn GE, Dobson V, Repka MX, Reynolds J, Kivlin J, Davis B, et al. Development of myopia in infants with birthweights less than 1251 grams. Ophthalmology 1992; 99: 329-40.

25 Gallo JE, Fagerholm P. Low grade myopia in children with regressed retinopathy of prematurity. Arch Ophthalmol 1993; 71: 519-23.

26 Robinson R, O'Keefe M. Follow up study on premature infants with and without retinopathy of prematurity. $\mathrm{Br} \mathcal{F}$ Ophthalmol 1993; 77: 91-4.

\section{Appendix Parent informed consent document}

\section{EYE PROBLEMS THAT PREMATURE BABIES}

DEVELOP

When a baby is born prematurely the blood vessels (arteries and veins).inside the eyes have not yet fully grown. During the first 2-3 months after birth (until about the time at which the baby was due to be born) these blood vessels continue to grow. In most babies the blood vessels grow normally and vision develops normally. However in some babies, particularly those who are very premature and very ill during the first few weeks of life, the blood vessels do not grow properly. In these babies the normal blood vessels stop growing 
about 2 months after birth, and unhealthy blood vessels start to grow instead. These unhealthy blood vessels can cause scarring of the nerves inside the eyes and this can permanently damage the vision.

It is possible to treat babies who have unhealthy blood vessels growing in their eyes. The baby is given an anaesthetic while in the premature baby unit, and the unhealthy parts inside the eyes are treated with very mild burns. The burns get rid of the unhealthy blood vessels, and allow healthy blood vessels to grow instead. The burns are produced by shining flashes of a very bright light (laser light) into the eyes. The treatment is normally performed only once, but occasionally a repeat treatment is needed 2-3 weeks afterwards.

The treatment takes 2-3 weeks to work, and it is not until 1-2 months after the treatment that we know whether it has worked or not. In a few babies the treatment does not work and the baby ends up with poor vision or even blindness. However, in most babies the treatment does work, and these babies develop good vision, although spectacles may be needed when they are older. 